\title{
Conicity Index as an Anthropometric Index of Central Obesity in the Prediction of Adult Bronchial Asthma; Correlation with Fractional Exhaled Nitrous Oxide Tests
}

\author{
Amjed H. Abbas ${ }^{1}$, Hayder Abdul-Amir Al-Hindy ${ }^{2}$, Shahlaa Kh. Chabuk ${ }^{1}$, Mazin J. Mousa ${ }^{2}$ \\ ${ }^{1}$ Ass. Prof., Hammurabi College of Medicine, University of Babylon/Iraq, \\ ${ }^{2}$ Ass. Prof., College of Pharmacy, University of Babylon/Iraq
}

\begin{abstract}
Obesity and bronchial asthma (BA) are two major health concerns. These entities have been further established by several meta-analyses. Still, these analyses denote to "general-obesity", that classically measured via body mass index (BMI), which is a broad measure unable to distinguish between lean musclebulk and body fats. Thus, other indices, should applied like waist perimeter, waist/hip ratio, and conicity index (CI), which are also reasonable, and normalized easily. Sufficient studies on the BA association with $\mathrm{CI}$ are lacking up till now. Our work was designed based on the theory that obesity worsens BA symptoms, aiming to evaluate the asthma relationships and CI.
\end{abstract}

Methodology: This is an observational-study conducted on 410 asthmatics consulting outpatient-respiratoryclinic. They were diagnosed by pulmonologists, then referred for spirometric pulmonary functions (SPF) and fractional exhaled nitric oxide (FENO) tests. Patients' weight, height and BMI were measured and accordingly divided into two-classes "nonobese and obese". The $X^{2}$-test was applied to analyze the associations among qualitative parameters. Level of significant acceptance was $5 \%$, and the analyses had completed by using the SPSS package.

Results: Mean \pm SD of weight, height, and BMI were $80.9 \pm 15.4,1.64 \pm 1.6$, and $30.8 \pm 5.4$, respectively. AObindices were $96.2 \pm 14.3,107.1 \pm 10.6,0.98 \pm 0.9$ and1.25 \pm 0.1 for waist, hip, W/HR, and CI respectively. The mean FENO-measures were $43.8 \mathrm{ppb}$. There was a significant variation in the means of PEF and FEV1/FVC only, although the FENO-tests were equivalent between the sexes.There was a strong association between CI with increasing age. The CI had a weak non-significant association with increasing FENO-results.

Conclusion: The conicity index as an anthropometric index of central obesity is not associated with the FENO test among adult asthmatic patients. There was non-significant variation between obese and nonobese groups. The $\mathrm{CI}$ is not useful in the prediction of adult BA.

Keywords: Asthma, obesity, conicity index, fractional exhaled nitric oxide test.

\section{Introduction}

Obesity and bronchial asthma (BA) are two major health-concerns, that accumulating evidences emphasizes

\section{Corresponding Author:}

Hayder AA. Al-Hindy

Ass. Prof., College of Pharmacy, University of

Babylon/Iraq

e-mail: phar.hayder.abdul@uobabylon.edu.iq the incidence of»obese-asthma phenotype»associated with refractory symptoms, poor control, reduced response to inhaled steroids, and inferior life quality specially in women ${ }^{1}$. It is anticipated that by 2025 , the number of asthmatics will reachup to 400 million globally ${ }^{2}$. Notably, these two entitieshave been further established by numerous meta-analysis ${ }^{3}$. Still, these analyses, denotes "general-obesity", that is classically measured via body mass index (BMI), which isa broad measure. BMI applied clinicallysince it is cheap and informal, 
but not allows the body fat distribution to be inspected. Specifically, BMI unable to distinguishlean muscle bulkfrom body fats ${ }^{4}$. Consequently, anthropometryother indices applied, including waist-perimeter, waist/height ratio and conicity-index (CI), which are reasonable, andnormalizedeasily ${ }^{5}$. Currently, abdominal-obesity (AOb), progressively concerned, as" a state-of-art" for having an extra-abdominal fat ${ }^{6}$. Whether AOb also plays a dynamic role in BA is still debatable, because of the limits inherent in the methodologies used in these studies ${ }^{7}$. Mean while, studies on the $\mathrm{AOb}$ association with BA are lackinghitherto. Given the above, ourwork designed based on the theory that obesity worsens BA symptoms, aiming to evaluates relationships between CI and BA.

\section{Methodology and Sampling}

This is an observational-study conducted on 410 asthmatic patients (212 males) attending outpatient-respiratory-clinic. The patients diagnosed by pneumologists based on a history besides either reversible airflow restriction (FEV1 $<70 \%$ predicted or preceding best, that improved by $>15 \%$ post $200 \mu \mathrm{g}$ $\beta$-agonist inhaler) and being at stage- 5 of the 'BTS/ SIGN-asthma-management-guidelines" ${ }^{8}$. Then, referred forprivate-clinics to read their spirometric pulmonary functions (SPF)and fractional exhaled nitric oxide (FENO) test (medisoft ${ }^{\circ}$, Belgium) for the severity of BA'. FENO-values were classified to "'low $(<25 \mathrm{ppb})$ and intermediate/high $(\square 25 \mathrm{ppb})$ " compatible to the ATS references ${ }^{10,11}$. Two measures were taken for each patient simultaneously and the mean was recorded. The study excluded patients with respiratory infection, chronic renal/cardiac illnesses, neurophysical-debility, any edematous condition, chest-deformity that would influence SPFs. Patients were divided according to their treatment history into treated and untreated group. Treatment history includes all anti-asthma medications: oral, systemic, inhaled, and injectable. Those on irregular therapies (poorly complaints) regarded as untreated. Patients further subdivided into two-classes 〈 nonobese and obese $)$ demarcated as $\mathrm{BMI} \leq 25$ and $\geq 30 \mathrm{~kg} / \mathrm{m}^{2}$,individually. The anthropometrics (weight, circumferences, and length) were obtained by standardized procedures with calibrated stadiometer and ground scale, assuming a maximum difference of 1.0 $\mathrm{cm}$ or $100 \mathrm{~g}$ between the replicated measures. For waist/ hip circumferences (WC/HC), and waist-to-hip ratio (W/HR), an elastic-tape was used; and for WC the tape placed at the least-circumference in between iliac crest and last ribcage ${ }^{12}$. All measurements were repeated and their means was depended finally. BMI Measures were obtained while the applicant wearing least cloths and barefooted. The applicants were barefooted also during tallness measurement. Valdez scientific-equivalence for CI calculation was applied ${ }^{13}$ :

$$
\text { Conicity Index }=\frac{\text { Waist Circumference }(\mathrm{m})}{0.109 \sqrt{\frac{\text { weight }(\mathrm{kg})}{\text { height }(\mathrm{m})}}}
$$

The study protocol was permitted by the EthicalCommittee of the hospital and Babylon-healthdirectorate. All the results were expressed as mean and either standard errors orstandard deviations. The $X^{2}$-test was applied to analyze the association among qualitative parameters. The level of significant acceptance was $5 \%$, and the analyses were completed using SPSS-software.

It is worth attention; our work had conducted during the era of two major-events on national and international levels. On national level: protests and riots, while on international levels COVID19-pandemic. Both were associated with transportation and internetnetwork difficulties,curfews, and road-barricades. These problems rendering many participants unable to complete their SPFs examination in the private-clinic, therefore, not all study parameters for all patients were completed.

\section{Results}

The main characteristics of the study had been expressed by table-1, which exposed mean age of $33.4 \pm 13$ with mean duration of BA of 8.02 year. The mean \pm SD weight, height and BMI were $80.9 \pm 15.4$, $1.64 \pm 1.6$ and $30.8 \pm 5.4$ respectively. Indices of $\mathrm{AOb}$ were $96.2 \pm 14.3,107.1 \pm 10.6,0.98 \pm 0.9$ and $1.25 \pm 0.1$ for waist, hip, W/HR, and CI one-to-one. The mean FENO were $43.8 \mathrm{ppb}$. 
Table-1: Mean, standard deviation, minimum and maximum measures of study parameters

\begin{tabular}{|l|c|c|c|c|c|c|c|c|c|c|}
\hline & $\begin{array}{c}\text { Age } \\
\text { (years) }\end{array}$ & $\begin{array}{c}\text { Duration } \\
(\mathbf{y e a r s})\end{array}$ & $\begin{array}{c}\text { Weight } \\
\mathbf{( k g )}\end{array}$ & $\begin{array}{c}\text { Height } \\
\mathbf{( m )}\end{array}$ & $\begin{array}{c}\text { BMI } \\
\mathbf{( k g / \mathbf { m } ^ { 2 } )}\end{array}$ & $\begin{array}{c}\text { Waist } \\
\mathbf{( \mathbf { c m } )}\end{array}$ & Hip (cm) & $\begin{array}{c}\text { W/H } \\
\text { Conicity } \\
\mathbf{I n d e x}\end{array} \begin{array}{c}\text { FENO } \\
\mathbf{p p b}\end{array}$ \\
\hline Mean & 33.4 & 8.02 & 80.9 & 1.64 & 30.8 & 96.2 & 107.1 & 0.89 & 1.25 & 43.8 \\
\hline Std. Deviation & 13 & 8.2 & 15.4 & 1.63 & 5.4 & 14.3 & 10.6 & 0.9 & 0.1 & 28.2 \\
\hline Minimum & 10 & 1 & 49 & 1.5 & 20 & 64 & 86 & 0.74 & 0.96 & 8 \\
\hline Maximum & 68 & 38 & 119 & 1.9 & 43 & 128 & 135 & 1.08 & 1.47 & 148 \\
\hline
\end{tabular}

Table-2 exposed the impact of gender-variation among the variables. The age, duration was comparable between sexes, while all anthropometric parameters were significantly higher in males except BMI and HC. There was a significant variation in the PEF and FEV1/FVC only, although the FENO tests were equivalent between sexes.

Table-2: Gender distribution of study anthropometric and spirometric parameters and their significance

\begin{tabular}{|c|c|c|c|c|c|c|c|c|c|c|c|c|c|c|c|}
\hline FENO & $\begin{array}{c}\text { FEV1/ } \\
\text { FVC }\end{array}$ & FVC & PEF & FEV1\% & $\begin{array}{c}\text { W/H } \\
\text { Ratio }\end{array}$ & Hip & Waist & $\begin{array}{c}\text { Conicity } \\
\text { Index }\end{array}$ & BMI & Height & Weight & Duration & Age & No & Gender \\
\hline $46.1 \pm 5.8$ & $78.9 \pm 1.1$ & $1.1 \pm 0.02$ & $82.6 \pm 2.30$ & $88.7 \pm 1.8$ & $0.94 \pm 0.01$ & $108.6 \pm 1.7$ & $103.2 \pm 2.4$ & $1.3 \pm 0.01$ & $30.3 \pm 0.9$ & $1.7 \pm 0.01$ & $88.2 \pm 2.9$ & $8.7 \pm 1.3$ & $32.9 \pm 1.7$ & 212 & Male (Mean \pm SE) \\
\hline $41.9 \pm 3.7$ & $75.3 \pm 1.2$ & $1.1 \pm 0.03$ & $71 \pm 23.5$ & $84.9 \pm 2.2$ & $0.89 \pm 0.01$ & $105.7 \pm 1.6$ & $90.2 \pm 1.9$ & $1.12 \pm 0.01$ & $30.9 \pm 0.8$ & $1.6 \pm 0.01$ & $76.7 \pm 2.1$ & $7.6 \pm 0.8$ & $33.7 \pm 1.6$ & 198 & Female (Mean \pm SE) \\
\hline$>0.05$ & 0.035 & $>0.05$ & 0.001 & $>0.05$ & 0.001 & $>0.05$ & 0.001 & 0.001 & $>0.05$ & 0.001 & 0.001 & $>0.05$ & $>0.05$ & $>0.05$ & P-Value \\
\hline
\end{tabular}

Table-3 revealed significant influence of the asthma treatment on FENO-readings. Those with no treatment history had about three-times chances to get severe asthma in terms of poor FENO results [P-0.034,95\% CI: 1.06-8.27].

Table-3: Variation in the Measurements of FENO According to the History of Treatment in Asthmatic Patients

\begin{tabular}{|l|c|c|c|c|c|}
\hline & \multicolumn{2}{|c|}{ Categories of FENO tests } & \multirow{2}{*}{ OR } & \multirow{2}{*}{ Significance } & \multirow{2}{*}{$\mathbf{9 5 \%}$ CI } \\
\cline { 2 - 3 } & $\mathbf{2 5 \mathbf { 2 5 p b }}$ & $\mathbf{2 5 \mathbf { 2 5 p b }}$ & & \\
\hline History of treatment (Mean $\pm \mathrm{SD})$ & $14.8 \pm 5.3$ & $43.2 \pm 17.6$ & \multirow{2}{*}{2.96} & \multirow{2}{*}{0.034} & \multirow{2}{*}{$1.06-8.27$} \\
\hline No history of treatment $(\mathrm{Mean} \pm \mathrm{SD})$ & $18.7 \pm 3.6$ & $59.3 \pm 29.5$ & & & \\
\hline
\end{tabular}

Both FENO and FVC measures exceptionally, revealed non-significant differences among obese-groups, otherwise other SPFs-indices significantly differed (table-4).

Table-4: Differences of spirometric pulmonary functions andFENO tests among study participants according to their obesity status

\begin{tabular}{|l|c|c|c|c|c|}
\hline FENO & FEV1/FVC & FVC & PEF & FEV1\% & Non-obese (Mean \pm SE) \\
\hline $31.8 \pm 5.2$ & $73.5 \pm 1.6$ & $1.1 \pm 0.05$ & $66.7 \pm 2.2$ & $78.3 \pm 2.1$ & Overweight $($ Mean \pm SE) \\
\hline $24.7 \pm 4.5$ & $77 \pm 1.4$ & $1.2 \pm 0.03$ & $78.9 \pm 2.8$ & $88.7 \pm 2.5$ & Obese (Mean \pm SE) \\
\hline $29 \pm 3.3$ & $79.2 \pm 1.2$ & $1.2 \pm 0.02$ & $81.5 \pm 3$ & $289.1 \pm$ & Significance \\
\hline$>0.05$ & 0.019 & $>0.05$ & 0.003 & 0.007 & \\
\hline
\end{tabular}

There was a positive-association between CI and participants' ages; were CI increased with increasing ages (figure-1B).Meantime, the CI had a weak non-significant association with increasing FENO-results (figure- 1A).

\section{Discussion}

To our knowledge, this is the first study inspecting AOb-indicators with adult asthma according to FENO (a marker of a topic inflammatory airways) in Babylon.
The correlation of $\mathrm{AOb}$ with FENO-tests in the adult BA-prediction lies at the heart of the discussion on this article. Asthma/airways-hyper responsiveness associated with obesity are matters of congoing-studies. However, the pathophysiological bases and causal/ 
effect factors are partly-understood. Our hypothesis is that the $\mathrm{AOb}$ (defined as $\mathrm{CI}$ ) is associated with the SPF and FENO-measures. Contrary to our hypothesis, data disclosed that FENO-values had non-significant variations between obese and nonobese groups, although, significant differences of SPFs-indices excluding FVC besides a high overall mean FENO-measures among the asthmatics (43.8ppb).Additionally, nonsignificant association between FENO-tests and CI was reported.

Our results are consistent to Flashner et al. findings, who showed both high and low BMI were related with lower FENO-values in his cohort ${ }^{14}$. Lang et al., stated that obesity (BMI $>95^{\text {th }}$ centile) had slight effect on symptoms, risk of acute attack or airway-markers among poorly-controlled asthmatic children ${ }^{1}$. The severity of disease was not significantly correlated with relative body-weight in a study involved children and adolescents in Poland ${ }^{15}$. Contrariwise, it might be argued that in obesity, higher mass of the abdominothoracic wall decreases "functional-residual-capacity" causing shortened smooth muscle of the air-passages. Likewise, obesity assume a breathing pattern of high-frequency and reduced flow-volume, which disposes them to higher airway-responsiveness. Appleton et al., from Australia, revealed that $\mathrm{AOb}$ increased the risk of developing adults asthma ${ }^{16}$.

In this section, the discussion will point to several probable elucidations of nonsignificant association of FENO-results with $\mathrm{AOb}$ among asthmatic adults.

First, in obese, higher levels of asymmetricdimethyl-arginine (ADM)compared to L-arginine (LA), might cause reduced FENO-measures. Late-onset asthmatic-adult revealed are verse relationship between $\mathrm{BMI}$ and $\mathrm{LA} / \mathrm{ADM}$ ratio ${ }^{17}$. This correlation was lost after adjustment for LA/ADM indicating possible arbitration of the association with FENO by LA/ADM. Both ADM/LAcan inhibit nitrous oxide (NO) ${ }^{18}$. Obesity has been publicized to be allied with elevated ADM level. Consequently, obese people may show low LA/ $\mathrm{ADM}$, and therefore lower $\mathrm{FENO}^{14}$.

Second, the males showed higher obesity parameters and worse FENO-values compared to females in this study. The studies displayed a larger influence of obesity on nonatopic BA specifically in females that may explain the stronger obesity-asthma linkseen in females compared with males ${ }^{19}$. Additionally, alack of association between obesity and adults allergy is also demonstrated by other scholars ${ }^{16}$.
One more explanation for the detected results of CI and FENO includes the effects of body size on pulmonary dynamics. It was found that a negative-association of FENO with BMI clarified partially by more narrow air-passages detected among obese-patients ${ }^{20}$. If the exhalation-rate at the mouth is kept constant, as in FENO-collection, those with narrow airways may have a higher airflow-velocity, decreasing transit time of alveolar gas in the airway, and reducing amount of NO exhaled ${ }^{21}$. Malnorished-asthmatics could have lowarginine measures, which is essential for NO-synthesis. Furthermore, those peoples may have low-thiamine levels that can disturb NO-synthesis by its effect on NO-synthase ${ }^{22}$. Moreover, it is possibly that effects of $\mathrm{AOb}$ result in the pulmonary-vascular-treevariations that lower $\mathrm{FENO}^{14}$. NO hasa vasodilatory activitiesby stimulation of Ca-dependent endothelial NO-synthase that cause vasodilatation ${ }^{23}$.

Lastly, I'm not alone-in my view-that obesity is a state of chronic inflammation, which is characterized by high levels inflammatory biomarkers like interleukin-6, and transforming growth factor-beta (TGF- $\beta)^{24}$. TGF- $\beta$ is a polypeptide-cytokine of multicellular activities ${ }^{25,26}$, formed by respiratory epithelium and stimulates fibroblasts-multiplication which may cause significant lung-fibrosis ${ }^{27}$. Previous studies demonstrated an increased TGF- $\beta 1$ in obstructive pulmonary disease $^{28}$. Macrophages and fibroblasts are vital in fibrogenesis and remodeling of respiratory-passages with uncertainpathway ${ }^{29}$. Hung, C. et al. reported an abnormal differentiation of monocytes into ' $\mathrm{PM}-2 \mathrm{~K}^{+}$ macrophage-like cell subclasses and fibrocytes"'along with high monocyte-derived TGF- $\beta 1$; characterized severe BA (i.e. poor SPFs). ${ }^{3}$

All anthropometric parameters were significantly higher in males apart from BMI and $\mathrm{HC}$, although significant variations in SPFs in terms of the means of PEF and FEV1/FVC but not FENO, were noticed. These outcomes are contradicting recent findings. Umławska W. revealed nonsignificant association between the asthma-severity and relative body weight regardless the age, with non-significant changes in SPFs between the two sexes although the girls had a significantly higher $\mathrm{AOb}^{15}$. Several revisions exposed a robust obesity correlation with asthma risk in women compared to $\operatorname{men}^{31,32,33}$. Obese women show reduced progesterone levels that may reduceß2-receptor activity, thereby reduce bronchodilation and worsen asthma symptoms. Weight reduction may upsurges progesterone and $\beta 2$ receptor density ${ }^{34}$. 
In this article, there was a significant CI increase with increasing ages correlated with nonsignificant association of FENO-tests with increasing age. Obesity can aggravate both age-linked physical deterioration and complications of other illnesses. The incidence of several health complications, like DM, hypertension, arthropathies, and vascular diseaseis connected with obesity in increasing age ${ }^{35}$. The effect of age and duration of BA on asthma exacerbation is highest with increasing age; but the age has a more impact than duration on severity of $\mathrm{BA}^{36}$. Notable, aging is linked with raised stiffness of the thoracic-wall, reduced pulmonary elasticrecoil, and weakened respiratory muscles ${ }^{37}$.

\section{Conclusions}

Conicity index as an anthropometric index of central obesity is not associated with FENO-testamong asthmatic adults. Conicity index is not useful in the prediction of adult BA.

Ethical Clearance: The Research Ethical Committee at scientific research by ethical approval of both MOH and MOHSER in Iraq.

\section{Conflict of Interest: None}

Funding: Self-funding

\section{References}

1. Jason E. Lang, Janet T. Holbrook RAW et al. Obesity in Children with Poorly-Controlled Asthma: Sex Differences. Pediatr Pulmonol. 2013;48(9):847-56. doi:doi:10.1002/ppul.22707.

2. Di Genova L, Penta L, Biscarini A, Di Cara G ES. Children with Obesity and Asthma: Which Are the Best Options for Their Management? Nutrients. 2018;10(11):1634.

3. Di Jiang LW CB and OC. Association between abdominal obesity and asthma: a meta-analysis. Allergy Asthma Clin Immunol. 2019;15(16):11.

4. Daniels SR KP MJ. The utility of body mass index as a measure of body fatness in children and adolescents: diferences by race and gender. Pediatrics. 1997;99:804-7.

5. Kim TN, Park MS, Kim YJ, Lee EJ, Kim MK, $\mathrm{Kim} \mathrm{JM}$ et al. Association of low muscle mass and combined low muscle mass and visceral obesity with low cardiorespiratory fitness. PLoS One. 2014;9(6):e100118.
6. Pinheiro-da Cunha RS. The establishment of the cutoff index taper, as a proposal for a simple anthropometric index to assess obesity and coronary risk estimation elevadono Brazilian Army. Esc Nac Saúde Pública Sergio Arouca, Rio Janeiro. 2011;2011((xv)):141 f.

7. Franceliane Jobim Benedetti VLB JMG and GBF. Anthropometric indicators of general and central obesity in the prediction of asthma in adolescents; central obesity in asthma. Nutr Hosp. 2015;32(6):2540-8.

8. Network BTSSIG. British guidelines on the management of asthma. Thorax. 2003;58(95).

9. Abbas Amjed Hassan1 HSS CSK. Fractional exhaled nitric oxide (FeNo) as physiological marker for diagnosis and follow up asthma in comparison with spirometric parameters. Indian Journal of Public Health Research \& Development. 2018;9(10):15.

10. de Abreu FC, da Silva Júnior JLR RM. The Fraction Exhaled Nitric Oxide as a Biomarker of Asthma Control. Biomark insights. 2019;14(1177271919826550). doi:doi. org/10.1177/1177271919826550

11. Qasim Jawad AL-Daami, Hala Saad Bash GHNHA-H. High-Sensitivity C - reactive protein Assessment in Bronchial Asthma: Impact of Exhaled Nitric Oxide and Body Mass Index. Sys Rev Pharm. 2020;11(3):705-711.

12. Luana Cupertino Milagres KOM, Diana Cupertino Milagres, Fernanda Silva Franco, Andréia Queiroz Ribeiro JF de N. Waist-to-height ratio and the conicity index are associated to cardiometabolic risk factors in the elderly population. Ciência \& Saúde Coletiva. 2019;24(4):12.

13. Valdez R, Seidell JC, Ahn YI WK. A new index of abdominal adiposity as an indicator of risk for cardiovascular disease. A cross-population study. Int J Obes Relat Metab Disord. 1993;17(2):77-82.

14. Flashner, B. M., Rifas-Shiman, S. L., Oken, E., Camargo, C. A., Platts-Mills, T. J., Workman, L., ... Rice MB. Obesity, sedentary lifestyle, and exhaled nitric oxide in an early adolescent cohort. Pediatr Pulmonology. 2019;55(2):503-509.

15. Wioleta Umławska. Adipose tissue content and distribution in children and adolescents with bronchial asthma. Respir Med. 2015;109(200):e207. 
16. Appleton S., Adams R., Wilson D. et al. Central obesity is associated with nonatopic but not atopic asthma in a representative population sample. J ALLERGY CLIN IMMUNOL. 2006;118(6):12841291.

17. Holguin F, Comhair SAA, Hazen SL et al. An association between 1 - arginine/asymmetric dimethyl arginine balance, obesity, and the age of asthma onset phenotype. Am J Respir Crit Care Med. 2013;187(2):153-159. doi:10.1164/ rccm.201207-1270OC

18. Wells SM HA. Asymmetric dimethylarginine induces oxidative and nitrosative stress in murine lung epithelial cells. Am J Respir Cell Mol Biol. 2007;36(5):520-528. doi:10.1165/ rcmb.2006-0302SM

19. Chen, Y., Dales, R., \& Jiang Y. The Association Between Obesity and Asthma Is Stronger in Nonallergic Than Allergic Adults. Chest. 2006;130(3):890-95. doi:10.1378/chest.130.3.890

20. King GG, Brown NJ, Diba $\mathrm{C}$ et al. The effects of body weight on airway calibre. Eur Respir J. 2005;25(5):896-901. doi:10. 1183/09031936.05.00104504

21. Ho LP, Wood FT, Robson A, Innes JA GA. The current single exhalation method of measuring exhales nitric oxide is affected by airway calibre. Eur Respir J. 2000;15(6):1009-1013.

22. Gioda CR, Capettini LSA, Cruz JS LV. Thiamine deficiency leads to reduced nitric oxide production and vascular dysfunction in rats. Nutr Metab Cardiovasc Dis. 2014;24(2):183-188.

23. Van Hove CE, Van Der Donckt C, Herman AG, Bult H FP. Vasodilator efficacy of nitric oxide depends on mechanisms of intracellular calcium mobilization in mouse aortic smooth muscle cells. Br J Pharmacol. 2009;158(3):920-930.

24. El-Alameey IR, Fadl NN, Hameed ER, Sherif LS AH. Clinical Relevance of Transforming Growth Factor- $\beta 1$, Interleukin-6 and Haptoglobin for Prediction of Obesity Complications in Prepubertal Egyptian Children. Maced J Med Sci. 2015;3(1):105-110. doi:10.3889/oamjms.2015.017

25. Hayder Makki Al-Hindy, Mazin J. Mousa AKS, Raghdan Z. Al-Saad WHSA-D. Relationship of levels of transforming growth factorbetal (TGF- $\beta 1$ ) to the levels of ferritin in blood of transfusion dependent $\beta$-thalassemia major patients with growth retardation: A case-control study. EurAsian J Biosci. 2020;14(1):521-552.

26. Fouad Shareef Dleikh, Ameera Jasim Al-Aaraji, Rebee Mohsin, Mazin Jaafar Mousa, Hayder Abdul-Amir Makki Al-Hindy BAA-K. Possible cause-and-effect linkage of transforming growth factor-beta1 and platelets derived growth factor$\mathrm{AB}$ with delayed anthropometric parameters in adolescent patients with Cooley's anemia: Cases vis control research strategy. EurAsian J Biosci. 2020;14(1):1119-1125.

27. Arkwright PD, Laurie S, Super $M$ et al. TGF- $\beta 1$ genotype and accelerated decline in lung function of patients with cystic fibrosis. Thorax. 2000;55:459462.

28. Judith C.W. Mak, Moira M.W. Chan-Yeung, Siu P. Ho, Kin S. Chan, Kahlin Choo, Kwok S. Yee, Chi H. Chau, Amy H.K. Cheung MSMI., Elevated plasma TGF- $\beta 1$ levels in patients with chronic obstructive pulmonary disease,. Respir Med. 2009;103(7):1083-1089. doi:10.1016/j. rmed.2009.01.005

29. Fish, J. E. \& Peters SP. Airway remodeling and persistentairwayobstructioninasthma.JAllergyClin Immunol. 1999;104(S0091674999005217):509_ 516.

30. Hung, C., Wang, C., Suen J et al. Altered pattern of monocyte differentiation and monocyte-derived TGF- $\beta 1$ in severe asthma. Sci Rep. 2018;8(919). doi:10.1038/s41598-017-19105-z

31. Han YY, Forno E CJ. Adiposity, fractional exhaled nitric oxide, and asthma in U.S. children. Am J Respir Crit Care Med. 2014;190(1):32-39.

32. Shah, R., \& Newcomb DC. Sex Bias in Asthma Prevalence and Pathogenesis. Front Immunol. 2018;9(2997.). doi:10.3389/fimmu.2018.02997

33. Yue Chen, Robert Dales, Mei Tang DK. Obesity May Increase the Incidence of Asthma in Women but Not in Men: Longitudinal Observations from the Canadian National Population Health Surveys,. Am J Epidemiol. 2002;155(3):191-197.

34. official publication of the American College of Allergy, Asthma, \& Immunology; quiz 291-3 347. The impact of estrogen and progesterone on asthma. Ann allergy, asthma Immunol. 2003;90(3):284291. doi:10.1016/S1081-1206(10)61794-2

35. Shilpa Amarya, MSc*, Kalyani Singh, PhD MS. Health consequences of obesity in the elderly. 
J Clin Gerontol Geriatr. 2014:1-5. doi:0.1016/j. jcgg.2014.01.004

36. Zein JG, Dweik RA, Comhair SA et al. Asthma Is More Severe in Older Adults. PLoS One. 2015;10(7):e0133490. doi:10.1371/journal.
37. Janssens JP, Pache JC NL. Physiological changes in respiratory function associated with ageing. Eur Respir J. 1999;13(1):197-205. pone. 0133490 